\title{
Mediatització i mítings durant la campanya a les eleccions autonòmiques valencianes de 2019: entre la «lògica mediàtica» i la «lògica política»*
}

Àlvar Peris Blanes

UNIVERSITAT DE VALÈnCIA

alvar.peris@uuv.es

ORCID: 0000-0002-2323-2766

Guillermo López García

UNIVERSITAT DE VALÈNCIA

guillermo.lopez/िuv.es

ORCID: 0000-0002-5701-2024

Lorena Cano Orón

UNIVERSITAT DE VALÈNCIA

lorena.cano@uv.es

ORCID: 0000-0003-4270-1924

Vicente Fenoll

UNIVERSITAT DE VALÈNCIA

vicente.fenollauv.es

ORCID: 0000-0002-5851-4237

Rebut: 14/01/2020

Acceptat: $12 / 04 / 2020$

\footnotetext{
* Aquest treball s'emmarca en el Projecte de R+D+i «Estrategias, agendas y discursos en las cibercampañas electorales: medios de comunicación y ciudadanos» (referència CS02016-77331-C2-1-R), concedit pel Ministeri d'Economia i Competitivitat per al període 2017-2020 i desenvolupat pel grup d'investigació Mediaflows (www.mediaflows.es).
} 


\section{RESUM}

Aquest article pretén analitzar com es desenvolupen els mítings electorals en un període d'intensa mediatització, en el qual els mitjans de comunicació i els polítics s'influeixen mútuament. Amb aquest objectiu, prenem com a referència les eleccions autonòmiques a la Comunitat Valenciana celebrades l'abril de 2019, que van coincidir per primera vegada amb unes eleccions generals, de manera que la campanya va adquirir més rellevància que en cites electorals anteriors. En aquest context, ens centrem en conèixer com es van dissenyar aquests mítings i quin impacte van tenir tant en les xarxes socials com en la televisió. Les dades es van obtenir mitjançant una anàlisi observacional de tipus qualitatiu dels mítings centrals dels principals partits concurrents als comicis (PP, PSPV-PSOE, Compromís, Ciudadanos, Unides Podem i Vox), que es va combinar amb una metodologia quantitativa per a l'anàlisi de contingut de les diferents publicacions que els partits esmentats i els seus líders van pujar als seus comptes oficials de Facebook i Twitter sobre aquests mítings, i amb l'estudi de la cobertura que la televisió pública valenciana, À Punt, en va oferir en els seus informatius. Els resultats indiquen, d'una banda, que els mítings electorals continuen sent esdeveniments molt ritualitzats que els partits polítics dissenyen pensant en com es difondran en un sistema mediàtic que ha canviat, s'ha fragmentat i diversificat, $i$ en què les xarxes socials estan adquirint cada vegada més importància. D'altra banda, la investigació apunta al fet que la informació sobre els mítings està, en part, encara controlada pels subjectes polítics. Una circumstància habitual en les campanyes electorals espanyoles.

Paraules clau: mítings electorals, mediatització, ritual polític, campanya electoral, eleccions autonòmiques.

ABSTRACT. Mediatisation and meetings during the campaign for the Valencian Regional Elections 2019: between 'media logic' and 'political logic'

This paper analyses how political rallies develop in an age of intense mediatisation in which politicians and media influence each other. In this connection, we look at the Regional Elections held in the Valencian Autonomous Community in April 2019. For the first time, these coincided with a General Election, so that even more was at stake than usual. We wanted to know how political rallies were designed and what impact they had on both social networks and on television. The data were obtained through a qualitative observational analysis of the key rallies of the main parties taking part in the elections (PP, PSOE, Compromís, Ciudadanos, Unidas Podemos, and Vox). We combined that approach with a quantitative methodology for content analysis of the various rally postings made by parties and their leaders on their official Facebook and Twitter accounts. We also studied $\dot{A}$ Punt's TV coverage of the same rallies in its news. On the one hand, the results indicate that election rallies continue to be highly ritualised events. Political parties carefully plan their rallies, always mindful of how these will be reported in today's highly fragmented media systems - especially in social networks. On the other hand, our study suggests that information on rallies is still tightly controlled by the parties - something that is commonplace in Spanish election campaigns.

Keywords: election rallies, political ritual, election campaign, regional elections.

\section{SUMARI}

Introducció: mediatització i ritualitat en els mítings electorals

Metodologia i hipòtesi d'investigació

Resultats de la investigació

- L'anàlisi observacional dels mítings

- Anàlisi dels mítings en les xarxes socials

- L'anàlisi televisiva dels mítings

Discussió i conclusions

Referències bibliogràfiques

Autor per a correspondència / Corresponding author: Àlvar Peris Blanes. Departament de Teoria dels Llenguatges i Ciències de la Comunicació Facultat de Filologia, Traducció i Comunicació Avda. Blasco Ibáñez, 32 - 46010, València (Espanya).

Citació suggerida / Suggested citation: Perís Blanes, A. et al. (2020). Mediatització i mítings durant la campanya a les eleccions autonòmiques valencianes de 2019: entre la «lògica mediàtica» i la «lògica política». Debats. Revista de cultura, poder $i$ societat, 134(1), 53-70. DOI: http://doi.org/10.28939/iam.debats.134-1.4 


\section{INTRODUCCIÓ: MEDIATITZACIÓ I RITUALITAT EN ELS MÍTINGS ELECTORALS}

Els rituals i els símbols són factors essencials de la comunicació política, segons han demostrat nombrosos estudis procedents, sobretot, de la sociologia i l'antropologia (Navarini, 2001). De fet, com sosté Mazzoleni, no existeix la política sense ritual, tot i que no tota la política pot reduir-se a aquesta dimensió: «El ritual és per dret propi un tipus de llenguatge polític, una manera de comunicar fortament formalitzat $\mathrm{i}$ ordenat per regles expressives que reflecteixen les estructures culturals d'una societat concreta o d'un context polític concret» (2010: 132). En certa manera, continua l'autor, el ritual polític és un llenguatge per mitjà del qual es manifesta la competició pel poder d'una manera tangible, visible i fins i tot teatral (Mazzoleni, 2010: 136). I si no hi ha política sense rituals, tampoc hi ha rituals sense símbols, entesos com els significats i valors no materials que envolten aquests rituals i que els aporten sentit i legitimació. Encara que tradicionalment s'ha considerat que la política moderna està determinada per actes estrictament racionals, d'un quant temps ençà són diversos els autors que han destacat la importància que ocupa l'ordre simbòlic i afectiu en tota acció política (Lakoff, 2016; Richards, 2010).

Des que tenim constància de la seua existència, les campanyes electorals constitueixen un moment simbòlic intens. S'hi despleguen una infinitat d'actes comunicatius ritualitzats mitjançant els quals canalitzar l'activitat política. No hi ha cap dubte que els mítings, aquelles trobades directes i multitudinàries en llocs públics en què el candidat o candidata pronuncia un discurs de naturalesa electoral davant la ciutadania (López García, Gamir Ríos i Valera Ordaz, 2018: 132), han sigut un dels actes més recurrents i amb més èxit. Per aquesta raó, en aquest treball ens proposem desenvolupar una anàlisi del seu paper en el context d'una campanya electoral i, més concretament, en les eleccions a autonòmiques de la Comunitat Valenciana celebrades l'abril de 2019, en una situació peculiar, ja que es va tractar de la primera ocasió en què les elecci- ons autonòmiques es van convocar per separat dels comicis municipals (i, a més, coincidint amb unes eleccions generals).

El propòsit dels mítings electorals, en el context d'una campanya electoral, ha canviat singularment en les últimes dècades. D'acord amb la classificació històrica proposada per Norris (2000), en les campanyes anomenades «premodernes», que coincideixen amb la primera fase de la comunicació política segons Blumler i Kavanagh (1999), l'objectiu del míting era congregar la ciutadania perquè el candidat o candidats d'un partit polític pogueren explicar les seues propostes i interactuar amb el públic. Aquest propòsit tenia sentit en un escenari en què, d'una banda, el públic estiguera prou polititzat com per a acudir a mítings polítics amb un interès genuí per conèixer el programa electoral d'algun candidat $i$, de l'altra, el míting complira una funció específica en la transmissió d'aquest missatge (el programa electoral del candidat) a la ciutadania. En tot cas, el míting contribuïa a reforçar la decisió del vot i aconseguia certa sensació de proximitat —almenys temporal i espacial- entre els polítics i els ciutadans, i més en un moment en què la influència dels mitjans de comunicació era escassa o incipient. Des d'aquesta perspectiva, els mítings eren rituals fonamentals per a traslladar el missatge polític a la ciutadania.

A partir dels anys cinquanta i seixanta del segle passat, la consolidació dels mitjans de comunicació en la transmissió del missatge polític, sobretot de la televisió, ha proporcionat nous models, nous llenguatges i nous usuaris als rituals i als símbols de la política. Com expliquen Dayan i Katz (1995), en aquesta etapa l'impacte dels rituals i les cerimònies en la societat està condicionat no pel fet d'haver-se produït, sinó per com es van representar mediàticament. La capacitat dels mitjans per a intercedir permanentment en el coneixement del món social per part de les persones ha rebut el nom de «mediatització» (Couldry i Hepp, 2013; Mazzoleni i Schulz, 1999). Aquest concepte, sobre el qual existeix una abundant literatura, no al-ludeix al paper que exerceixen els mitjans de comunicació com a 
simples «mediadors» entre els esdeveniments i el públic, ni tampoc tracta de definir o quantificar els efectes del missatge mediàtic en l'audiència. El que pretén és analitzar críticament les interdependències dels mitjans amb altres actors culturals, socials i polítics a l'hora d'interpretar la realitat (Hepp, Hjarvard i Lundby, 2015; Esser i Strömback, 2014).

Sobre la mediatització existeixen dues aproximacions teòriques que estan acostant posicions recentment (Couldry i Hepp, 2013: 196). D'una banda, la que fa referència a la «lògica mediàtica», és a dir, al fet que els mitjans imposen unes formes de representació a la resta d'actors socials, el protagonisme informatiu dels quals dependrà de la seua capacitat per a ajustar-s'hi. Això afectarà especialment els subjectes polítics, que hauran de dissenyar les seues accions com a esdeveniments mediàtics amb l'objectiu que siguen transmesos al conjunt de la societat. D'altra banda, l'enfocament que apel-la, des de la perspectiva constructivista (Berger i Luckmann, 1996), a la importància que posseeixen els mitjans en el modelatge comunicatiu de la realitat social i cultural. Aquest plantejament emfatitza que els humans interpretem i experimentem el món social gràcies al conjunt de missatges, discursos, imatges, textos i sons amb què ens creuem al llarg de la nostra vida, i que aquests, en les societats modernes, provenen majoritàriament dels mitjans de comunicació, amb els quals convivim diàriament i de forma molt intensa. El poder de «crear» la realitat que s'atribueix als mitjans incideix, especialment, en la idea de procés, de contingència històrica i en la seua complexitat institucional i tecnològica.

En aquells anys, les campanyes electorals entren en la seua etapa de «modernització» (Norris, 2000), en què els canvis més evidents aniran de la mà d'una creixent mediatització. S'ha arribat a parlar de media campaigns o campanyes mediàtiques per a explicar aquestes transformacions que en ocasions ignoren la importància que encara exerceixen els subjectes polítics en el seu disseny i execució (Mazzoleni, 2010). En qualsevol cas, ens trobem en un període en què es professionalitza l'organització i la comunicació de les campanyes de la mà de noves figures, com els assessors polítics i spin doctors; es desenvolupa i sofistica el màrqueting polític i electoral, que aconsegueix la maduresa (Maarek, 2009); i la gestió de la imatge ja no és un luxe a l'abast d'uns quants, sinó que es converteix en un imperatiu per a l'èxit electoral, en coherència amb la irrupció de la televisió com a instrument privilegiat per a la transmissió i legitimació del discurs polític. Aparèixer en televisió serà, a ulls dels electors, el principal reconeixement de pertinença al «paisatge polític» (Maarek, 2009).

En aquesta segona fase, les exigències i ritmes del nou i popular mitjà televisiu contribuiran a augmentar l'espectacularitat i la fragmentació de la informació política, dins i fora de les campanyes electorals. De totes maneres, pel seu caràcter dramàtic i lúdic, les conteses electorals seran el terreny propici per a aquesta «representació» en clau espectacular (Edelman, 1988). El gènere més conegut de propaganda televisiva serà l'anunci, que es convertirà en un emblema de les campanyes modernes, així com els debats entre els candidats (Canel, 2006; Barranco Sáiz, 2010). La preponderància de la imatge afavoreix, al mateix temps, que l'atenció recaiga sobre el candidat i es desplace el partit polític del centre dels missatges. Aquesta «personalització» (Bennett, 2012) i xoc de líders en què es converteix la carrera política es combina amb la implementació d'estratègies d'entreteniment que converteixen la informació política en accessible per a audiències àmplies. Des d'aleshores, els missatges senzills i simples, l'ús de registres propis del llenguatge militar o esportiu, les declaracions breus en forma de titulars impactants (els anomenats sound bites) i l'apropament sensacionalista a la vida privada dels candidats (Casero Ripollés, Ortells Badenes y Rosique Cedillo, 2017; Holtz Bacha, 2003), són pràctiques habituals de la informació política en televisió. Aquestes pràctiques conflueixen, amb el temps, en el gènere de l'«infoentreteniment» (Thussu, 2007; Langer, 2000), que té infinitat de variants i que, en relació amb el discurs polític en particular, podem rastrejar en espais merament informatius, com són els noticiaris o en entrevistes, però també en programes pròxims a l'entrete- 
niment, com els talk shows o els magazins (Berrocal Gonzalo, 2017; Mazzoleni i Sfardini, 2009).

Aquest escenari electoral cada vegada més mediatitzat (més dependent dels mitjans per a transmetre i explicar tot allò que succeeix en la campanya) ha derivat en un menor interés del públic per assistir als discursos dels polítics en campanya, cosa que ha donat lloc a un format de míting diferent i prefabricat. Des de fa dècades, els mítings s'organitzen com espectacles configurats per als mitjans de comunicació (Contreras, 1990), amb el propòsit que el partit exhibisca «múscul» (és a dir, mostre el suport de la ciutadania als seus postulats) i d'incorporar els seus missatges a l'agenda dels mitjans. D'aquesta manera, el públic dels mítings ha passat a estar compost quasi exclusivament per militants i simpatitzants del partit que omplin l'aforament, i que serveixen perquè els partits facen una demostració de força davant els espectadors i lectors dels mitjans de comunicació. De manera que el míting ja no s'organitza per a convèncer cap dels presents, perquè ja estan convençuts prèviament, sinó per a convéncer —o almenys influir- el públic que no assisteix al míting i el segueix, distretament, en la seua versió resumida canalitzada pels mitjans. Si ho expressem en termes d'estratègia electoral, el míting ha passat de ser un acte polític organitzat per a la «conquesta» a ser un acte més de «posició» (Mazzoleni, 2010: 150). En tot cas, i encara que la «conquesta» del vot ja no requerisca mítings (i activistes), aquests no perden la seua essència ritual $\mathrm{i}$ «teatralizant».

Per últim, en el tercer estadi de la comunicació política, que és on ens trobem actualment, la campanya electoral ha passat a experimentar un major grau de mediatització —si és possible- en què no només participen els mitjans, sinó també els dirigents polítics i la mateixa ciutadania, que ara transmet missatges i interactua a través de les noves formes de comunicació digital. Segons han determinat diverses investigacions, les causes de la mediatització de la política són complexes i abundants. Strömback (2008), per exemple, entén la mediatització actual com un procés que es produeix en quatre fases i en què els mitjans també són influenciats per la resta d'actors polítics. En aqueix sentit, allò rellevant per a l'autor és conèixer el grau d'interdependència de la política i la societat respecte dels mitjans (Strömback, 2008: 228). Mazzoleni i Schulz ja van plantejar quelcom molt similar fa alguns anys (1999: 247), quan van argumentar que, tot i que els mitjans ocupen un espai central en la vida política contemporània, les institucions polítiques encara mantenen el control i les funcions dels processos polítics. Per tot això, en aquest treball pretenem conèixer quines són les característiques, funcions i objectius dels mítings en l'actualitat, així com el seu grau de mediatització en les campanyes electorals contemporànies.

\section{METODOLOGIA I HIPÒTESI D'INVESTIGACIÓ}

Per tal de complir el nostre propòsit realitzarem una anàlisi dels mítings centrals de les principals forces polítiques que van concòrrer a les eleccions autonòmiques a la Comunitat Valenciana, celebrades el 28 d'abril de 2019: PSPV-PSOE, PP, Compromís, Ciudadanos, Unides Podem i Vox. Hem triat l'àmbit valencià perquè aquest territori va tenir un pes singular en aquell procés electoral, atès que va ser l'única comunitat autònoma on van coincidir les eleccions generals amb els comicis autonòmics, que es van avançar per decisió del president de la Generalitat, Ximo Puig. Aquesta coincidència, d'alguna manera, va condicionar els partits polítics a tenir més presència en terres valencianes de la que potser haurien mostrat si només s'hagueren celebrat eleccions generals. De fet, dels cinc partits nacionals, dos (PSOE i Ciudadanos) van triar València per a tancar la seua campanya electoral el divendres 26 d'abril, i un altre (el PP) va organitzar un míting aquell mateix dia pel matí (encara que el tancament de campanya pròpiament dit se celebraria després a Madrid). Una circumstància que no sol ser habitual en processos electorals d'aquesta importància, en què Madrid acostuma a ser el centre informatiu.

En primer lloc, abordarem l'anàlisi dels mítings a partir d'una aproximació qualitativa resultant de 
l'observació presencial de cadascun d'ells, amb l'excepció del míting de tancament de campanya de Compromís del dia 26 d'abril (en el seu lloc, assistim al que pot considerar-se també acte central de campanya de la coalició valencianista a València, el dissabte 13 d'abril). Prestarem especial atenció a l'organització de l'esdeveniment, al disseny escenogràfic, als temes més incisius i a qualsevol altre detall d'ordre simbòlic i ritual que només es pot conèixer si $\mathrm{s}^{\prime} \mathrm{hi}$ assisteix personalment.

A continuació coneixerem quina ha sigut la gestió comunicativa que els partits polítics han fet d'aquests mítings en les xarxes socials, particularment en Facebook i Twitter. Hem triat aquestes xarxes socials per ser les més utilitzades a Espanya avui dia (The Social Media Family, 2019). La recol-lecció del corpus de Twitter i Facebook ha sigut possible gràcies a l'aplicació Netlytic, que ens ha permés descarregar tots els tuits i posts publicats en temps real en els comptes públics dels partits polítics i dels seus principals líders. S'han recopilat tots els tuits i posts publicats el dia del míting central a València i els de l'endemà, amb l'objectiu d'analitzar tots aquells que comentaven l'esdeveniment. En total, el corpus està compost per un total de 640 tuits i 85 posts. Posteriorment, l'anàlisi de xarxes socials ha sigut manual, a partir d'una anàlisi de contingut de metodologia quantitativa.

Per últim, comprovarem la cobertura i el seguiment que s'ha fet d'aquests mítings en els informatius de la televisió pública valenciana, À Punt. Amb aquest objectiu, hem analitzat com ha tractat aquests esdeveniments el principal informatiu de la cadena autonòmica emès just després del míting, tant si corresponia a la primera com a la segona edició. Atendrem qüestions d'índole discursiva referents al text i a la imatge per a saber què prioritzen i què destaquen les cadenes en la informació sobre els mítings de cadascuna de les formacions polítiques. Cal destacar que la informació electoral està marcada pel repartiment de temps que imposa la Junta Electoral Central (JEC) i guarda una relació proporcional amb els resultats de cada partit en les eleccions anteriors.
A partir d'aquesta anàlisi, en què emprem diferents metodologies - una anàlisi de contingut de tipus quantitatiu i una aproximació qualitativa de tipus discursiva i observacional一, volem plantejar les següents preguntes i hipòtesis d'investigació:

H1: Els mítings s'han transformat en actes més reduïts que no estan dirigits principalment al públic assistent, sinó que busquen generar contingut amb el qual alimentar els mitjans de comunicació, tant les televisions com les xarxes socials.

Q1: En aquest sentit, continuen els mítings sent actes rituals importants en les campanyes electorals d'avui dia, especialment per a les forces polítiques emergents?

Q2: Tenint en compte que la Junta Electoral Central marca els temps informatius que les cadenes de televisió poden dedicar a informar sobre els partits polítics durant les campanyes electorals en l'actualitat, quin grau de mediatització té la informació que realitzen sobre els mítings?

\section{RESULTATS DE LA INVESTIGACIÓ}

\section{L'anàlisi observacional dels mítings}

La coalició valencianista Compromís va celebrar el seu míting central a València a l'inici de la campanya, el dissabte 13 d'abril, en un escenari obert situat al Jardí del Túria, a l'altura del Palau de la Música. L'escenari permetia que el públic s'aglutinara en diverses ones o anells: els més pròxims, asseguts, la resta, al voltant, dempeus. L'acte va congregar els referents de la coalició i es va centrar en els candidats dels dos processos electorals en marxa: Joan Baldoví, cap de llista per València, i Mónica Oltra, candidata a la presidència de la Generalitat. En una campanya que va agafar a Compromís a contrapeu (la coalició es va oposar fèrriament a l'avançament electoral decidit pel president de la Generalitat, Ximo Puig), l'acte va tenir el paper de reactivar la militància i els simpatitzants en una campanya que 
es percebia a contracorrent, mesclada amb els comicis de les eleccions generals, en les quals Compromís obtenia tradicionalment resultats molt pitjors que en les eleccions autonòmiques i municipals. A més d'aquest míting, els candidats de Compromís van tornar a València per al tancament de campanya, el dia 26.

Quant a les candidatures d'àmbit nacional, la primera a celebrar el seu míting central a València va ser l'altra coalició de la mostra: Unides Podem, el dimecres 17 d'abril. Estava previst que el míting se celebrara al port de València, però va haver-hi canvis d'última hora i finalment es va celebrar a una de les naus de Fira València. Un escenari un poc gris i sense encant (fora de València, en una gegantesca nau industrial buida) que va contribuir a deslluir el míting en conjunt, sobretot si es compara l'afluència (similar, en tot cas, a la d'altres partits amb representació semblant a València, com Ciudadanos o Compromís) amb la de l'històric míting al Pavelló de la Fonteta, corresponent al procés electoral de desembre de 2015, que va congregar més de 10.000 persones (en què s'inclouen les que van omplir el recinte i unes 2.000 que es van quedar fora). En l'escenari, un cercle situat en el centre, al voltant del qual es va asseure el públic, es van succeir els oradors (vam comptar fins a tretze persones que van intervenir en el míting) fins a l'arribada del protagonista indiscutible, Pablo Iglesias, que va filar un discurs pensat per a apel-lar a la sorpresa i al caràcter genuí d'Unides Podem com a formació progressista bolcada en els interessos de la ciutadania (la «gent», en la terminologia habitual d'Unides Podem), a qui Iglesias demanava «una oportunitat».

Un dia abans del tancament de campanya va tenir lloc el míting de Vox al Museu Príncep Felip de la Ciutat de les Ciències. Un míting molt esperat en termes mediàtics, atesa l'expectació que havia aconseguit generar la formació ultradretana, tant per les seues expectatives electorals com per l'èxit dels mítings que celebraven a diferents localitats. En tots ells, com destacava Vox en les seues xarxes socials, s'omplia per complet l'aforament, fins a tal punt que sempre es quedava gent fora que no podia entrar, a la qual el líder de Vox, Santiago Abascal (o el dirigent d'aquesta formació que figurara com a orador principal), es dirigia breument amb un megàfon per a donar-los atenció.

Aquest relat dels fets no només es difonia a través de les xarxes socials de Vox, sinó també dels mitjans de comunicació que cobrien l'acte, que habitualment coincidien amb el discurs del míting ple «de gom a gom», de l'èxit de convocatòria sense pal-liatius. Ignorem quines van ser les circumstàncies reals a la resta dels mítings organitzats per aquesta formació, però podem afirmar que en el cas del míting de València, el relat del ple absolut del recinte, amb gent que es quedava fora, no es corresponia amb la realitat. De fet, Vox va tancar les portes per a accedir al míting quan encara quedava un terç del recinte per cobrir, i malgrat això, es va reproduir l'escena habitual: Santiago Abascal es va dirigir a la gent que s'havia quedat fora (unes 500 persones) mitjançant un megàfon, i després va començar el míting.

Quant al míting en si (amb una afluència, indubtablement, molt superior a la de qualsevol altre partit, a excepció del PSOE), va comptar amb tres oradors: el candidat a la presidència de la Generalitat, José María Llanos; el cap de llista per València en les eleccions generals, Ignacio Gil Lázaro; i el líder de Vox, Santiago Abascal. Precisament quan anava a començar aquest últim orador, Vox va tornar a obrir les portes perquè poguera entrar la gent que s'havia quedat fora. Tots ells van accedir sense problemes i, tot i així, continuava havent-hi espai lliure en el recinte, cosa que va plasmar el grau d'escenificació «ritualitzada» que havíem experimentat en el míting de Vox: una litúrgia, parlar al públic que s'havia quedat fora mitjançant un megàfon, amb un obvi propòsit propagandístic que no es corresponia amb la realitat.

Els tres partits polítics restants van celebrar els seus mítings a València l'últim dia de la campanya, el divendres 26 d'abril. No obstant això, en el cas del PP no pot dir-se que fóra el míting de tancament de 
campanya, que se celebraria a Madrid. El PP havia organitzat un míting el divendres a la vesprada on s'esperava la presència del líder nacional, Pablo Casado, però finalment aquest es va decantar per tancar a Madrid, així que el PP va preparar ràpidament un míting el divendres al matí al recinte Marina Beach Club, amb la participació de Casado, i va mantenir el seu míting de tancament de la campanya autonòmica el divendres a la vesprada. Una duplicitat de mítings en un mateix dia que va suscitar una clara imatge d'improvisació i discrepàncies entre la direcció nacional i la valenciana d'aquest partit. En el míting de la Marina, a més, Pablo Casado va arribar amb una hora de retard, cosa que va obligar els oradors previs a estendre's més temps davant d'un públic escàs (més o menys la meitat de l'aforament, de 400 persones). L'escenificació, més que mostrar múscul, en va mostrar l'absència i va evidenciar problemes i desavinences.

Ciudadanos va realitzar el seu acte de tancament de campanya a València, exactament al mateix lloc que Compromís: el Jardí del Túria, a l'altura del Palau de la Música. Es tracta, sense cap dubte, del menys convencional de tots els mítings que analitzem: a més del míting en si, Ciudadanos va organitzar activitats al Jardí del Túria durant tot el dia, entre les que s'incloïa una carrera entre els candidats del partit (que, en una metàfora més que previsible, va guanyar Albert Rivera). En el míting en si van participar, a més de Rivera, el candidat a la presidència de la Generalitat, Toni Cantó, la cap de llista per València, María Muñoz, i els candidats per Madrid, Inés Arrimadas i Edmundo Bal. Malgrat l'escenografia festiva, no es va aconseguir un èxit notable d'afluència de públic (hi va assistir més o menys el mateix públic que al míting de Compromís dues setmanes abans, unes 2.000 persones).

Finalment, el PSOE va celebrar el seu míting de tancament de campanya al Parc Central de València. El dels socialistes va ser, en diversos aspectes, el míting més similar als d'antany de tots els que hem analitzat. Va ser el que va aconseguir més afluència de públic (unes 10.000 persones) i va presumir d'una organització impecable, que explica aquesta afluència, nodrida de militants i simpatitzants de les agrupacions socialistes valencianes. Els participants en el míting van ser la candidata a l'alcaldia de València, Sandra Gómez (malgrat que les eleccions municipals no estaven en lliça); el ministre de foment i secretari d'organització del PSOE, José Luis Ábalos; el president de la Generalitat, Ximo Puig, i el candidat a president del Govern, Pedro Sánchez. L'arribada de Sánchez, perfectament orquestrada, es va produir durant el míting. Sánchez va entrar pel fons del recinte i va caminar a través del corredor central, saludant els i les militants socialistes que s'amuntegaven entorn d'ell i l'aplaudien, fins a arribar a l'escenari. La seua entrada va durar més de cinc minuts i va servir per a mostrar, com la resta del míting, el missatge de fortalesa i confiança en els resultats electorals que transmetien incessantment els oradors.

\section{Anàlisi dels mítings en les xarxes socials}

Com es pot comprovar, els partits polítics van utilitzar bastant els seus comptes en xarxes socials per a difondre informació sobre els mítings que anaven a celebrar. Dels 640 tuits publicats entre el dia del míting i el posterior per part de tots els partits, 298 (47\%) van ser publicacions sobre l'esdeveniment. Com es pot veure en la Taula 1, la candidata de Compromís a la presidència de la Generalitat valenciana, Mónica Oltra (69 \%) i Ciudadanos (84\%) destaquen per ser la política i el partit que més van promocionar els mítings de les seues formacions a través de Twitter .

En el cas de Facebook, dels 85 posts inicials publicats pels partits i candidats entre el dia del míting i el posterior, 32 (38 \%) van ser publicacions sobre l'esdeveniment. Encara que es tracta d'un volum clarament inferior al de Twitter, destaquen algunes dades, com que Compromís va dedicar el total de posts a la promoció i la gestió comunicativa del seu míting central. El PSPV-PSOE i el seu candidat Ximo Puig es van moure en xifres molt similars al voltant del $50 \%$, igual que Ciudadanos i el seu candidat Toni Cantó, que és el polític que més posts va publicar 
Taula 1 Cobertura del míting a València a través dels comptes de Twitter.

\begin{tabular}{|c|c|c|c|c|c|}
\hline $\begin{array}{c}\text { Partit / } \\
\text { Candidatura }\end{array}$ & $\begin{array}{l}\text { Data } \\
\text { míting }\end{array}$ & $\begin{array}{c}\text { Dates } \\
\text { analitzades }\end{array}$ & $\begin{array}{c}\text { Quantitat de } \\
\text { tuits }\end{array}$ & $\begin{array}{l}\text { Tuits sobre } \\
\text { miting a VLC }\end{array}$ & $\begin{array}{c}\% \text { dels } \\
\text { publicats } \\
\text { aquells dies }\end{array}$ \\
\hline Compromís & 13 abril & 13 i 14 abril & 89 & 48 & $54 \%$ \\
\hline Mónica Oltra & 13 abril & 13 i 14 abril & 62 & 43 & $69 \%$ \\
\hline PP & 26 abril & 26 i 27 abril & 58 & 27 & $47 \%$ \\
\hline Isabel Bonig & 26 abril & 26 i 27 abril & 7 & 4 & $57 \%$ \\
\hline PSPV-PSOE & 26 abril & 26 i 27 abril & 54 & 23 & $43 \%$ \\
\hline Ximo Puig & 26 abril & 26 i 27 abril & 24 & 6 & $25 \%$ \\
\hline Ciudadanos & 26 abril & 26 i 27 abril & 70 & 59 & $84 \%$ \\
\hline Toni Cantó & 26 abril & 26 i 27 abril & 48 & 15 & $31 \%$ \\
\hline Unides Podem & 17 abril & 17 i 18 abril & 146 & 39 & $27 \%$ \\
\hline $\begin{array}{c}\text { Rubén Martínez } \\
\text { Dalmau }\end{array}$ & 17 abril & 17 i 18 abril & 21 & 2 & $10 \%$ \\
\hline Vox & 25 abril & 25 i 26 abril & 26 & 16 & $62 \%$ \\
\hline $\begin{array}{l}\text { José María } \\
\text { Llanos }\end{array}$ & 25 abril & 25 i 26 abril & 35 & 16 & $46 \%$ \\
\hline
\end{tabular}

Font: Elaboració pròpia.

durant aquells dies (11) i que més va parlar sobre el míting (6), fet que demostra la intensa activitat del polític en les xarxes. En la part negativa, destaca Unides Podem i el seu líder, Rubén Martínez Dalmau, que van publicar molt pocs posts sobre el míting ( $20 \%$ i $17 \%$ ), tot i comptar amb dos dels comptes més actius en aquesta xarxa social, amb 10 i 6 posts respectivament. El mateix ocorre amb Vox, que dels 18 posts publicats només 3 van estar dedicats al míting (17\%). Per la seua banda, José María Llanos, el seu candidat a la Generalitat, estranyament no va tenir activitat en aquesta xarxa durant aquells dies tan intensos per a la seua formació.
A partir de les dades obtingudes es pot afirmar que, per al seguiment d'aquesta mena d'esdeveniments, Twitter és l'eina més utilitzada, la qual cosa no és d'estranyar, atesa la naturalesa de l'aplicació, que permet arribar a més persones a través d'etiquetes públiques que canalitzen les converses sobre un tema concret. Així i tot, l'ús de Twitter és particular en alguns comptes corporatius, perquè s'utilitzen per a amplificar els missatges publicats, bé pel partit que publica a l'àmbit estatal, bé pels polítics estrela, tant a l'àmbit estatal com autonòmic. Aquest és el cas, principalment, del compte de Ciudadanos a la Comunitat Valenciana, en què només el $14 \%$ 
Taula 2 Cobertura del míting a València a través de Facebook

\begin{tabular}{|c|c|c|c|c|c|}
\hline $\begin{array}{c}\text { Partit / } \\
\text { Candidatura }\end{array}$ & $\begin{array}{l}\text { Data } \\
\text { míting }\end{array}$ & $\begin{array}{c}\text { Dates } \\
\text { analitzades }\end{array}$ & $\begin{array}{l}\text { Quantitat } \\
\text { de posts }\end{array}$ & $\begin{array}{l}\text { Posts sobre } \\
\text { mitting en VLC }\end{array}$ & $\begin{array}{c}\% \text { dels } \\
\text { publicats } \\
\text { aquells dies }\end{array}$ \\
\hline Compromís & 13 abril & 13 i 14 abril & 3 & 3 & $100 \%$ \\
\hline Mónica Oltra & 13 abril & 13 i 14 abril & 7 & 3 & $43 \%$ \\
\hline PP & 26 abril & 26 i 27 abril & 11 & 4 & $36 \%$ \\
\hline Isabel Bonig & 26 abril & 26 i 27 abril & 5 & 3 & $60 \%$ \\
\hline PSPV-PSOE & 26 abril & 26 i 27 abril & 6 & 3 & $50 \%$ \\
\hline Ximo Puig & 26 abril & 26 i 27 abril & 6 & 3 & $50 \%$ \\
\hline Ciudadanos & 26 abril & 26 i 27 abril & 2 & 1 & $50 \%$ \\
\hline Toni Cantó & 26 abril & 26 i 27 abril & 11 & 6 & $55 \%$ \\
\hline Unides Podem & 17 abril & 17 i 18 abril & 10 & 2 & $20 \%$ \\
\hline $\begin{array}{c}\text { Rubén Martínez } \\
\text { Dalmau }\end{array}$ & 17 abril & 17 i 18 abril & 6 & 1 & $17 \%$ \\
\hline Vox & 25 abril & 25 i 26 abril & 18 & 3 & $17 \%$ \\
\hline $\begin{array}{c}\text { José María } \\
\text { Llanos }\end{array}$ & 25 abril & 25 i 26 abril & 0 & 0 & $0 \%$ \\
\hline
\end{tabular}

Font: Elaboració pròpia.

de les publicacions sobre el míting era contingut original (51 tuits dels 59 publicats sobre el míting aquells dies són retuits d'altres comptes oficials del partit). Així mateix, Vox i Compromís també utilitzen aquest recurs, però en menor mesura. En el cas d'Unides Podem, PSPV-PSOE i PP, a penes s'empra.

Quant al tipus de contingut compartit en xarxes, és una pràctica comuna per a la cobertura del míting unir dos tipus de missatges: 1) citar frases del candidat a la presidencia del Govern espanyol que acudeix al míting, així com del candidat a la Generalitat, que solen ser el resum dels punts forts dels seus programes; i 2) divulgar fotografies, vídeos i textos d'agraïment que reafirmen l'èxit de la convocatòria i, per tant, de la victòria política assolida, si més no en termes mediàtics. D'aquesta manera, el míting sempre és un «gran ple» que demostra les bones expectatives electorals de la formació (Imatge 1).

\section{L'anàlisi televisiva dels mítings}

Per a començar l'anàlisi audiovisual, i seguint l'ordre cronològic, el partit que va celebrar el primer míting central de campanya va ser Compromís, el 13 d'abril al matí. En aquesta ocasió és l'informatiu del migdia, que comença a les 14:30 hores, el que va cobrir l'acte. El míting de la formació valencianista, celebrat al jardí del riu Túria, prop del Palau 


\section{Imatge 1 Publicacions en xarxes socials sobre l'èxit del míting}

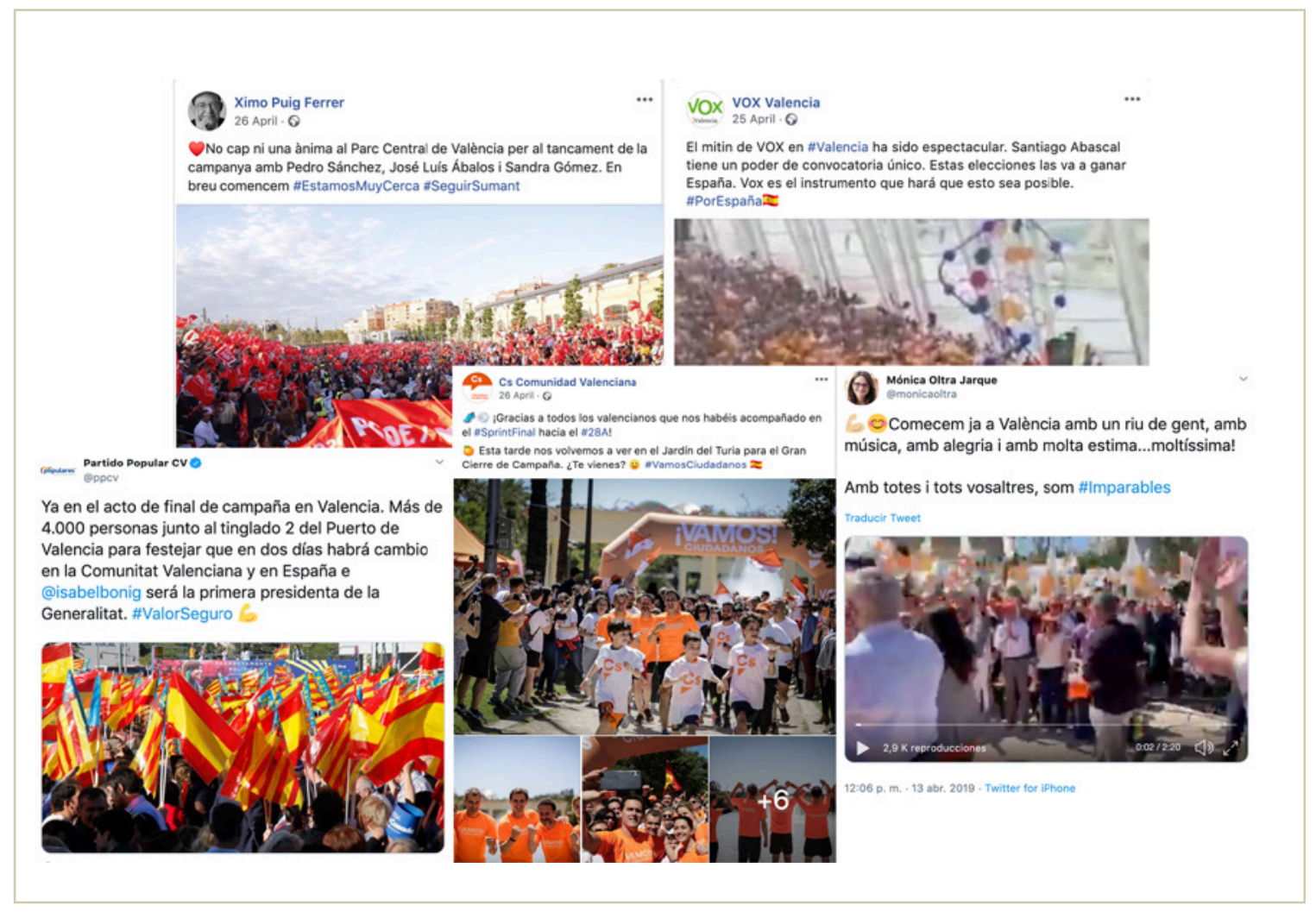

Font: Contingut publicat en Twitter i en Facebook.

de la Música, va obrir l'informatiu i va ser destacat en els titulars, amb una imatge dels principals líders del partit acostant-se a l'escenari mentre saludaven i aplaudien a la militància i simpatitzants. També es van poder observar diversos plans generals de l'escenari i del públic que l'envoltava.

El míting de Compromís (04:02 minuts) també va obrir el bloc de campanya, malgrat no ser el partit amb més representants en les Corts Valencianes, un fet certament inusual que no es va tornar a repetir amb la resta de formacions. Es va fer una connexió en directe per a informar de l'acte, que ja havia acabat. La reportera va desgranar algunes de les propostes anunciades, com la creació d'una oficina per a recuperar els diners de la corrupció o la gratuïtat del menjador escolar. Durant la crònica es van emetre diversos plans generals de l'escenari i del públic onejant les banderes del partit i alguna senyera valenciana. Es va transmetre una imatge triomfal i festiva amb els talls de veu del candidat per Castelló, Vicent Marzà, i per Alacant, Aitana Mas. També d'Oltra, que va ser rebuda amb crits de «presidenta, presidenta». La informació va finalitzar amb un pla de tots els candidats somrients aplaudint als assistents, que onejaven les banderes mentre sonava la música de campanya. A la crònica s'hi van sumar noves imatges del míting per a 
introduir temàticament les eleccions generals i el candidat per València al Congrés dels Diputats, Joan Baldoví, que va reclamar, per mitjà d'un tall de veu, un finançament autonòmic millor.

Per seua part, el míting central d'Unides Podem, celebrat el 17 d'abril a un pavelló de Fira València, també va obrir el bloc de campanya en els titulars de l'informatiu de la nit d'aquell dia, que començava a les 20:30 hores. En la imatge es podia veure el candidat a la presidència del Govern de la formació, Pablo Iglesias, entrant al recinte, visiblement satisfet, i saludant a militància i simpatitzants. Després es van emetre diversos plans oberts dels candidats damunt d'un escenari circular prou menut, i de la gent que l'envoltava. A diferència de Compromís, el míting d'Unides Podem no va obrir el bloc de campanya, sinó que va aparéixer en l'ordre que li corresponia d'acord amb la representació en les Corts, darrere de PP, PSPV-PSOE, Compromís i Ciudadanos. La informació del míting va ocupar la totalitat de la crònica (02:18 minuts), amb una intervenció gravada per una periodista que estava fent el seguiment des del lloc de l'acte. Al fons s'apreciava Iglesias durant la seua intervenció i els assistents, que van omplir un recinte més aviat xicotet. La veu en off anava explicant algunes de les propostes de la formació, com ara obrir les fosses del franquisme, tancar els CIE (Centres d'Internament per a Estrangers), regular el preu dels pisos de lloguer i augmentar el salari mínim interprofessional.

Tant Iglesias com el candidat a la presidència de la Generalitat, Rubén Martínez Dalmau, van apel·lar al vot útil i van arremetre contra les anomenades «clavegueres» de l'Estat. Es va emetre un tall de veu de cadascun. Martínez Dalmau es mostrava d'esquena, amb un fons gens significatiu, mentre que Iglesias apareixia de cara mentre insistia en la senzillesa de les propostes del seu partit. Durant la crònica es van veure diverses imatges dels dos polítics agafats per la cintura, somrients i amb el puny en alt, així com del públic assistent, que agitava banderes del partit i alguna republicana cridant «sí se puede». La perspectiva i l'angle de les imatges desprenien en tot moment la sensació d'un recinte ple.

A continuació, va ser el torn de Vox, que va fer el míting central a la Comunitat Valenciana el 25 d'abril a la vesprada. En la televisió pública valenciana, la notícia sobre el míting (32 segons) va aparèixer en l'últim lloc del bloc dedicat a la campanya electoral de l'edició de l'informatiu de la nit. En aquell moment, Vox encara no tenia representació en el Parlament autonòmic valencià. La cobertura va consistir en un suport d'imatges gravades en mòbil del míting, amb el rètol «Vox celebra l'acte central a València i ompli el Museu de les Arts i les Ciències». En la informació es va assenyalar la participació en el míting del líder nacional del partit, Santiago Abascal, rebut al crit de «presidente». Abascal apareixia en les imatges mentre avançava amb dificultat cap a l'escenari, en un recinte abarrotat de persones que l'aclamaven, l'aplaudien i el gravaven amb el mòbil. La presentadora també va comentar el nombre d'assistents, més de cinc mil. Quant al contingut polític de l'acte, es va destacar la proposta de Vox de reduir dràsticament l'administració pública i els impostos, les crítiques a la llei de violència de gènere i la defensa del valencià de les Normes d'El Puig.

Les altres tres formacions, PP, PSOE i Ciudadanos, van celebrar el míting central el 26 d'abril, l'últim dia de la campanya. De fet, tant per al PSOE com per a Ciudadanos en va ser també el tancament. Precisament, el bloc de campanya de l'informatiu de la nit de la cadena pública va arrencar amb una crònica de l'acte del PP a la Marina de València (03:20 minuts). La informació començava amb una connexió en directe amb el míting, que en aquell moment ja s'havia acabat, en què la reportera informava d'algunes de les propostes plantejades en l'acte, com ara la reforma del codi penal per a aplicar la pena de presó permanent revisable. També destacava la crida de la candidata a la presidència de la Generalitat, Isabel Bonig, a la concentració del vot del centre dreta per garantir la unitat d'Espanya. El directe, amb el títol «Tancament de campanya del PP», estava il-lustrat 
amb imatges de l'acte, on es veia els polítics del PP a l'escenari.

El directe donava pas a un extracte del míting de Bonig, qui assegurava que la Comunitat Valenciana «és un mur de contenció del nacionalisme». Després de les declaracions apareixia una crònica del míting que s'havia celebrat al matí a la mateixa Marina de València, i que en realitat estava concebut com a míting central, on el candidat a la presidència del Govern espanyol, Pablo Casado, va demanar aglutinar el vot del centre dreta perquè no guanyara el PSOE, el qual —assegurava- havia pactat amb els independentistes catalans l'indult dels polítics catalans presos. El vídeo recollia l'afirmació de Casado que el seu partit «és garantia de creació d'ocupació». També destacava la proposta del PP de baixar els impostos a la classe mitjana o la formació d'un govern «a l'andalusa», format per PP, Ciudadanos i Vox. Les imatges del míting pertanyien al senyal realitzat pel partit, on s'apreciava, sobretot, els candidats sobre el fons de la costa valenciana i on a penes hi havia imatges del públic. L'espai on se celebrava l'acte electoral del PP era prou reduït en comparació amb el de la resta de partits. Es dóna la circumstància que el míting del matí també s'havia recollit en l'informatiu de migdia i va ocupar tot el temps dedicat a la informació electoral del PP, així que va ser un acte molt aprofitat.

Per la seua banda, la informació sobre el PSOE en l'informatiu de la nit (02:31 minuts) d'aquell mateix dia consistia en una connexió en directe des de l'acte de tancament de campanya al Parc Central de València. El reporter va comentar que, segons el candidat a la presidència de la Generalitat, Ximo Puig, el fet de celebrar el tancament de campanya a València revelava la importància que tenia per a Sánchez aquesta comunitat. També destacava la crida al vot dels indecisos que feien des del partit socialista per a frenar les dretes. El directe portava el text «Puig i Sánchez tanquen campanya a València» i anava acompanyat d'imatges del públic i de l'ambient festiu que hi havia a l'acte mentre el públic esperava que arribaren els candidats.
El directe donava pas a un vídeo que mostrava els preparatius de l'espai on se celebraria el míting. Es va incidir, de nou, en el caràcter simbòlic que tenia celebrar l'últim acte de campanya al Parc Central, un espai que havia sigut un dels emblemes polítics del canvi de govern, tant a la ciutat com en la Generalitat. Segons Puig, l'objectiu era reivindicar la gestió realitzada a la Comunitat Valenciana durant la legislatura que acabava i el compromís del partit socialista amb el «corredor mediterrani». No obstant això, la declaració de Puig no pertanyia al míting, sinó a un acte anterior. Tampoc es va veure a Sánchez en el míting, de manera que la seua presència no es va aprofitar informativament. A continuació es va parlar de les visites de Sánchez a Castelló i Alacant durant la campanya electoral, amb imatges dels candidats en aquests mítings. En el vídeo també va apareixia Sánchez en un acte electoral del mateix dia a Toledo, en què retreia a PP i Ciudadanos que hagueren abraçat les mentides de l'extrema dreta i demanava el vot als indecisos. Aquestes imatges pertanyien al senyal per satèl-lit que va oferir el propi partit.

Per a acabar, en la cobertura del tancament de campanya de Ciudadanos a València (02:07 minuts), À Punt va fer una connexió en directe als jardins del Palau de la Música. Dins del bloc de campanya i en la posició que li tocava d'acord amb els seus representants parlamentaris, la reportera va comentar el nombre d'assistents al míting i va destacar el missatge d'unitat i igualtat que havia llançat Inés Arrimadas en la seua intervenció. El títol del directe era «Rivera i Cantó tanquen també a València» $\mathrm{i}$ en les imatges, cedides pel partit, s'observava l'arribada dels candidats entre aplaudiments en un espai ple de gent. El directe donava pas a un vídeo que recollia la carrera organitzada al matí per Ciudadanos a la mateixa ciutat de València, que també ocupava tot el temps dedicat a informar sobre les activitats d'aquest partit en l'informatiu de migdia. Al final d'aquell acte, Rivera va afirmar que es tracta de l'últim sprint abans de les eleccions que el convertirien en president d'un govern liberal, constitucionalista i sense separatistes, que faria Sánchez fora de la Moncloa. 
A la nit es va emetre el mateix tall de veu que ja s'havia emès al matí i no es van veure declaracions del míting central celebrat a poqueta nit. En les imatges del vídeo es podien veure els candidats de Ciudadanos corrent en grup pel vell llit del riu Túria, amb Rivera arribant primer a la meta, en una clara metàfora de la carrera electoral.

\section{DISCUSSIÓ I CONCLUSIONS}

Segons hem pogut comprovar en aquesta investigació, la diversitat d'opcions electorals, l'abundància de dispositius tecnològics a través dels quals transmetre informació i la pèrdua de centralitat dels mitjans de comunicació han contribuït a modificar la fisonomia pròpia dels mítings electorals.

Des d'aquesta perspectiva, i com a resposta a la H1, en aquesta tercera fase de la comunicació política el míting ja no es configura com un espectacle pensat únicament per a obtenir rèdits en els mitjans de comunicació (tot i que aquest propòsit continua estant molt present), sinó que també és un mecanisme per a cohesionar el públic afí i mostrar-los la força i l'entusiasme del partit, així com la seua convicció en la victòria. El motiu que el míting tinga aquest paper és, fonamentalment, que els mitjans de comunicació han canviat, s'han fragmentat i s'han diversificat (Chadwick, 2013). El que s'observa és que, a diferència d'allò que succeïa en fases anteriors, ara el míting s'ha transformat en un esdeveniment que, a més d'ocupar temps televisiu, té derivacions importantíssimes en les xarxes socials, de manera que la seua escenificació ja no depèn només de l'interés i del criteri dels mitjans tradicionals, sinó que està directament relacionat amb l'estratègia del partit polític.

Com que aquests partits ja no compten amb la capacitat de mobilització del públic afí que tenien en el passat, o bé, senzillament, no els compensa l'esforç que requereix, ideen noves formes i nous espais on celebrar els seus actes de campanya, amb la vista posada en els mitjans (els «vells» i els «nous»), però ara amb la capacitat de determinar més que abans quins missatges i, sobretot, quines imatges es pretén projectar entre l'electorat. Com hem vist, aquesta estratègia comporta, en general, prioritzar actes més xicotets (més barats i més fàcils d'omplir), per tal d'ocupar l'agenda informativa i generar un flux de missatges constant dirigit no només als mitjans, sinó també a la mateixa militància i al públic general. El contingut programàtic desglossat en el míting, en aquest sentit, queda prou desvirtuat, perquè es parla per a qui ja està convençut $i$, en realitat, per a la seua digestió mediàtica posterior, ja que no cal assistir presencialment per a informar-se d'allò que s'hi esdevé.

Els mítings de les eleccions autonòmiques d'abril de 2019 a la Comunitat Valenciana en són una bona mostra. Amb l'excepció del míting del PSOE i potser del de Vox, aquests actes ja no es corresponen amb les grans demostracions de força dels partits polítics de no fa gaire temps, quan omplir la Plaça de Bous de València semblava a l'abast de molts d'ells, i fins i tot un partit, el PP, es va atrevir a omplir l'estadi de futbol de Mestalla l'any 1996. De totes maneres, i malgrat comptar amb dissenys escenogràfics una mica diferents d'allò habitual i de la incorporació de noves estratègies comunicatives, els mítings continuen sent esdeveniments rituals que els partits polítics duen a terme per a, d'una banda, transmetre una imatge d'èxit i triomf cap als seus seguidors i el conjunt de la societat i, de l'altra, proveir els mitjans de contingut dins de la «lògica mediàtica» a què fèiem al-lusió. En conseqüència, els actes continuen planificant-se amb l'objectiu de ser tan espectaculars com siga possible; la «personalització» dels mítings es manté molt elevada; les intervencions dels participants es prefereixen curtes i impactants; i els gestos d'ordre simbòlic que han caracteritzat històricament aquest tipus de celebracions - com ara l'agitació de banderes o l'entrada dels líders a l'escenari del míting entre aplaudiments i salutacions- es mantenen incòlumes.

En la investigació que hem dut a terme, i com a resposta a la Q1, aquesta sensació s'aprecia en tots els mítings, encara que alguns hagen resultat més 
satisfactoris que la resta. Per exemple, des d'aquest punt de vista, el del PSOE va ser, sense dubte, el més afavorit en la comparativa. No només per congregar més gent, sinó per la imatge de triomf i d'expectatives de victòria que va aconseguir transmetre en les al-locucions dels oradors i en l'ambient general. Caldria dir el mateix del míting de Vox, amb ingredients rituals $\mathrm{i}$ «teatrals» perfectament prefabricats per a generar il-lusió col-lectiva entre els seguidors. Dins d'aquesta il-lusió s'hi inclouria el missatge de «ple a vessar» que volia transmetre en tots els seus actes durant la campanya i que, segons hem pogut demostrar, era només parcial. Quant a la resta de partits, dos d'ells, Compromís i Ciudadanos, van complir les expectatives amb mítings optimistes i oberts (a més, els dos en el mateix espai), molt canònics en tots els aspectes, tot i que amb alguna innovació (la carrera de Ciudadanos), mentre que els altres dos (Unides Podem i PP), en part a causa d'errors d'organització i canvis de plans d'última hora (el PP va haver de fer un segon míting per a compensar el «fracàs» del primer), van oferir una imatge sense encant que, almenys a través de la televisió, és difícil d'apreciar, perquè ja es van encarregar els equips de comunicació d'«assessorar» i proveir les cadenes de televisió amb les imatges més adequades perquè l'acte estiguera representat de la millor manera possible.

Des del punt de vista mediàtic, per la seua banda, els mítings van complir perfectament la seua missió, ja que van generar un considerable trànsit de missatges en xarxes socials, que els mateixos partits i candidatures es van encarregar de dinamitzar (tot i que alguns més que uns altres), i especialment van tenir un important ressò en televisió, ja que van ocupar tot el temps dedicat per la cadena pública À Punt a informar sobre cada partit dins del bloc de campanya. No obstant això, crida l'atenció la cobertura que va rebre el míting de Compromís, que va obrir l'informatiu d'aquell dia i el bloc electoral posterior, quan teòricament — i d'acord amb la Junta Electoral Central- no li tocava. També és ressenyable la duració de la peça, més llarga que la de les informacions dels mítings de la resta de partits, i la quantitat d'intervencions dels líders de la formació valencianista
(4), igualment superiors a les de la resta de partits. No sabem a què va obeir aquella pràctica, perquè en les següents informacions de la campanya À Punt va seguir escrupolosament allò establert per la JEC. D'altra banda, trobem que mítings com els del PSOE i Ciudadanos no es van explotar televisivament com segurament pretenien els promotors. De fet, en À Punt no vam veure cap intervenció dels líders d'aquestes dues formacions durant l'acte central de la campanya, sinó que les intervencions mostrades pertanyen a actes anteriors. Es tracta d'un fet sorprenent si tenim en compte que el míting se celebra en bona part per a proporcionar unes imatges televisives d'impacte al voltant del líder i del partit amb la intenció de motivar l'electorat.

És possible que aquests partits hagen comprés que es juguen molt més en les xarxes socials que en la televisió convencional, i que hagen posat més interés a difondre aquests continguts en l'entorn digital. El nombre de tuits publicats sobre els mítings indica una alta freqüència de missatges que donaria suport a aquesta tesi, especialment si ens fixem en els comptes de Ciudadanos a la Comunitat Valenciana i del seu líder, Toni Cantó, que es mostren molt actius, si bé no ocorre el mateix amb els perfils en Twitter de PSPV-PSOE i Ximo Puig. Precisament, altres partits es mostren més participatius en aquesta plataforma. I tampoc Facebook sembla un canal informatiu de primer ordre, tot i que sí és cert que tots partits i el seus líders empren aquesta xarxa social per a parlar sobre el míting. La sensació és, de totes maneres, que malgrat l'acreditat benefici que aporten aquestes eines per al màrqueting polític (Bode i Vagra, 2017), les investigacions realitzades sobre el cas espanyol indiquen que la majoria de líders dels principals partits polítics i els seus equips encara desaprofiten les potencialitats creatives i comunicatives de les xarxes socials (López García i Valera Ordaz, 2017). Aquest treball apuntaria també en la mateixa direcció.

Per últim, i en resposta a la Q2, s'observa que el grau de mediatització en el cas dels mítings és complex i les interdependències entre mitjans i polítics apunten en totes dues direccions (Hjarvard, 2016). Així doncs, 
d'una banda, la cobertura del míting de Compromís en À Punt podria indicar un cert grau d'autonomia de la televisió pública a l'hora d'informar sobre la campanya electoral i, en conseqüència, seria un exemple de la voluntat del mitjà per marcar l'agenda informativa. Aquesta mediatització «alta» també es percep clarament en el fet que els mítings encara són dissenyats pels partits pensant en com els difondran els mitjans. Per aquesta raó, en referència a l'escenografia i contingut, no només tenen en compte la televisió, sinó cada vegada més les xarxes socials, on la imatge i el vídeo adquireixen molta rellevància.

D'altra banda, no podem ignorar que la cadena pública valenciana, després del míting de Compromís i des d'aleshores fins al final, es va ajustar escrupolosament a allò que estableix la JEC quant a l'ordre i al temps previst per a informar de la campanya. A més, no va tenir objeccions a parlar d'aforament «complet» en referir-se al míting de Vox, quan sabem que això no era cert. En aquella ocasió, la televisió va preferir seguir la «lògica de partits» en lloc del criteri periodístic més elemental, que era assegurar-se de la veracitat de la informació. Des d'aquest punt de vista, el subjecte polític va imposar al mitjà els seus interessos i objectius (la mediatització va ser «del partit al mitjà»), una pràctica que és coherent amb allò establert per altres investigacions que han analitzat en els últims anys la mediatització a Espanya, on la informació continua estant controlada pels partits, sobretot durant les campanyes electorals (Casero Ripollés, Feenstra y Tormey, 2016; Valera Ordaz, 2015; Casero Ripollés, Izquierdo Castillo y Doménech Fabregat, 2014). No obstant això, altres estudis (Martínez Nicolás, Humanes i Saperas, 2014) assenyalen que es percep un canvi de tendència i apunten cap a una creixent autonomia dels mitjans espanyols a l'hora d'abordar la informació política. Una autonomia que sembla que, en el cas dels mitjans públics, hauria de ser imprescindible.

\section{REFERÈNCIES BIBLIOGRÀFIQUES}

Barranco Sáiz, F. J. (2010). Marketing político y electoral. Madrid: Pirámide.

Bennett, L. W. (2012). The Personalization of Politics: Political Identity, Social Media, and Changing Patterns of Participation. The Annals of the American Academy of Political and Social Science, 644(1), 20-39.

Berger, P. L. i Luckmann, T. (1996). La construcció social de la realitat: Un tractat de sociologia del coneixement. Barcelona: Herder.

Berrocal Gonzalo, S. (coord.) (2017). Politainment: La política espectáculo. València: Tirant lo Blanch.

Blumler, J. i Kavanagh, D. (1999). The Third Age of Political Communication: Influences and Features. Political Communication, 16(3), 209-230.

Bode L. i Vagra, E. K. (2017). Studying Politics across Media. Journal of Political Communication, 35(1), 1-7.

Canel, M. J. (2006). Comunicación política: Una guía para su estudio y práctica. Madrid: Tecnos.

Casero Ripollés, A.; Feenstra, R. A.; Tormey, S. (2016). “Old and new media logics in an electoral campaign: The case of Podemos and the two-way street mediatization of politics", The International Journal of Press/Politics, 21(3), 378-397.

Casero Ripollés, A., Izquierdo Castillo, J. i Doménech Fabregat, H. (2014). From Watchdog to Watched Dog: Oversight and Pressures between Journalists and Politicians in the Context of Mediatization. Trípodos, 34, 23-40.

Casero Ripollés, A., Ortells Badenes, S. i Rosique Cedillo, G. (2017). La disolución de las viejas fronteras: La fusión entre información y entretenimiento en el periodismo político. En A. Casero Ripollés i P. López Rabadán (ed.), Periodistas y políticos en España (p. 119-142). Barcelona: UOC. 
Contreras, J. M. (1990). Vida política y televisión. Madrid: Espasa Calpe.

Couldry, N. i Hepp, A. (2013). Conceptualizing Mediatization: Contexts, Traditions, Arguments. Communication Theory, 23, 191-202.

Chadwick, A. (2013). The Hybrid Media System: Politics and Power. Nova York: Oxford University Press.

Dayan, D. i Katz, E. (1995). La historia en directo: La retransmisión televisiva de los acontecimientos. Barcelona: Gustavo Gili. Edelman, M. (1988). Constructing the Political Spectacle. Chicago: Chicago University Press.

Esser, F. i Strömback, S. (ed.) (2014). Mediatization of Politics: Understanding the Transformation of Western Democracies. Nova York: Palgrave McMillan.

Hjarvard, S. (2016). Mediatización: La lógica mediática de las dinámicas cambiantes de la interacción social. La Trama de la Comunicación, 20(1), 235-252.

Hepp, A., Hjarvard, S. i Lundby, K. (2015). Mediatization: Theorizing the Interplay Between Media, Culture and Society. Media, Culture \& Society, 37(2), 314-324.

Holtz Bacha, Ch. (2003). Comunicación política: Entre la privatización y la espectacularización. Diálogo Político, $1,137-154$.

Lakoff, G. (2016). Política moral: Cómo piensan progresistas y conservadores. Madrid: Capitán Swing.

Langer, J. (2000). La televisión sensacionalista: El periodismo popular y las «otras noticias». Barcelona: Paidós.

López García, G., Gamir Ríos, J. i Valera Ordaz, L. (2018). Comunicación política: Teoría y enfoques. Madrid: Síntesis.

López García, G. i Valera Ordaz, L. (ed.) (2017). Pantallas electorales: El discurso de partidos, medios y ciudadanos en la campaña de 2015. Barcelona: UOC.

Maarek, Ph. J. (2009). Marketing político y comunicación: Claves para una buena información política. Barcelona: Paidós.

Martínez Nicolás, M., Humanes, M. L. i Saperas, E. (2014). La mediatización de la política en el periodismo español: Análisis longitudinal de la información política en la prensa de referencia (1980-2010). Trípodos, 34, 41-59.

Mazzoleni, G. (2010). La comunicación política. Madrid: Alianza Editorial.

Mazzoleni, G. i Schulz, W. (1999). Mediatization of Politics: A Challenge for Democracy? Political Communication, 16(3), 247-261.

Mazzoleni, G. i Sfardini, A. (2009). Politica Pop: Da «Porta a Porta» a «L'isola dei famosi». Bolonya: Il Mulino.

Navarini, G. (2001). Le forme rituali della política. Roma-Bari: Laertza.

Norris, P. (2000). A Virtuous Circle: Political Communication in Postindustrial Societies. Cambridge: Cambridge University Press.

Richards, B. (2010). News and the emotional public sphere. En S. Allan (Ed.) The Routledge Companion to News and Journalism. Nova York: Routledge, 301-311.

Strömback, J. (2008). Four Phases of Mediatization: An Analysis of Mediatization of Politics. The International Journal of Press/Politics, 13(3), 228-246.

The Social Media Family (2019). V Informe del uso de las redes sociales en España. Recuperat de https://thesocialmediafamily. com/informe-redes-sociales/

Thussu, D. K. (2007). News as Entertainment. Londres: Sage.

Valera Ordaz, L. (2015). La influencia de los partidos políticos españoles en las agendas de medios y blogs durante la campaña electoral de 2011. Communication \& Society, 28(3), 115-135.

\section{NOTA BIOGRÀFICA}

\section{Àlvar Peris Blanes (València, 1976)}

Professor ajudant doctor de Comunicació Audiovisual a la Universitat de València. Els seus principals interessos com a investigador se centren en la relació entre identitats i mitjans i en l'anàlisi de l'entreteniment televisiu i la política. Ha publicat nombrosos treballs sobre comunicació, estudis culturals i història. Participa com a investigador en el R+D Mediaflows. 


\section{Guillermo López García (Zaragoza, 1976)}

Doctor en Comunicació Audiovisual i professor titular de Periodisme a la Universitat de València. La major part de la seua investigació s'ha dirigit a l'estudi de l'opinió pública i de la comunicació per Internet. Coordina el Grup de R+D Mediaflows (www.mediaflows.es), especialitzat en l'anàlisi del paper dels mitjans de comunicació en processos electorals.

\section{Lorena Cano Orón (Quart de Poblet, 1991)}

Doctora en Comunicació i Interculturalitat per la Universitat de València (2019). Forma part de l'equip investigador de dos grups de R+D estables: Mediaflows i Scienceflows. Les seues línies d'investigació estan orientades a l'estudi dels fluxos de contingut en les xarxes socials en els àmbits de la salut i la comunicació política.

\section{Vicente Fenoll (Torrent, 1970)}

Doctor en Comunicació (2015) i professor associat a la Universitat de València. És membre dels grups d'investigació Mediaflows i CamforS. En l'àmbit de la investigació se centra en l'anàlisi de la comunicació digital. Ha realitzat estades d'investigació a universitats d'Alemanya (Erfurt, Ilmenau, Münster i Magúncia), l'Argentina (Còrdova) i Xile (Valdivia). 